\title{
Workplace ergonomic assessment pada komunitas pekerja internet marketing society
}

\author{
Ekha Rifki Fauzi*, Riski Rizal Palino \\ Prodi Teknologi Rekayasa Elektro-medis, Fakultas Sains \& Teknologi \\ Universitas PGRI Yogyakarta \\ Email Korespondensi: *ekharifkifauzi@upy.ac.id
}

Received August 15, 2021; Revised September 4, 2021; Accepted September 6, 2021

\begin{abstract}
Abstrak
Penggunaan regular komputer di ruang kerja berkontribusi menderita banyak faktor risiko yang berhubungan dengan musculoskeletal disorders (MSDs). Pekerjaan dengan komputer berisiko tinggi menderita berbagai macam keluhan, termasuk mempunyai tiga faktor risiko terbesar antara lain: postur punggung, pengulangan, dan kekuatan statis. Salah satu faktor pencegahan MSDs dengan menerapkan prinsip ergonomi di tempat kerja. Pencegahan menjadi hal yang harus diprioritaskan untuk menangkal berbagai macam efek negatif yang dapat timbul di tempat kerja. Tindakan pencegahan dapat minimalisir dampak negatif dari risiko-risiko utama diatas. Tujuan penelitian ini melakukan penilaian dan pengukuran keluhan dan pengetahuan tentang ergonomi dari pekerja Internet Marketing Society. Penelitian pengabdian ini menggunakan metode observasional dari hasil survey dengan kuesioner yang di distribusikan melalui google form. Total responden sebanyak 33 pekerja dari Internet Marketing Society. Hasil menunjukkan jika 54,5\% pekerja tidak tahu tentang ergonomi, 75,8\% pekerja tidak menggunakan alat pendukung penyangga pergelangan dan lengan. Pada masalah keluhan menyatakan pekerja sebagian besar mengalami nyeri otot $27,3 \%$ dan nyeri punggung $24,2 \%$, serta $24,2 \%$ pekerja mengalami kondisi bahu yang tidak rileks saat sedang bekerja. Pemberian pengetahuan dan informasi secara komprehensif terkait ergonomi tentu dapat menekan keluhan-keluhan dari pekerja agar terhindarkan dari MSDs. Kemudian, penekanan keselamatan dan kesehatan kerja harus diutamakan saat sedang bekerja agar terhindar dari kecelakaan atau penyakit akibat kerja.
\end{abstract}

Kata Kunci: Ergonomi; Utamakan keselamatan; Internet marketing society; MSDs

Abstract
Regular use of computers in the workspace contributes to suffering from many risk factors associated with musculoskeletal disorders (MSDs). High-risk computer jobs suffer from a wide variety of complaints, including having three of the biggest risk factors: back posture, repetition, and static strength. One of the prevention factors for MSDs is by applying the principles of ergonomics in the workplace. Prevention is something that must be prioritized to counteract various kinds of negative effects that can arise in the workplace. Preventive measures can minimize the negative impact of the main risks above. The purpose of this study is to assess and measure complaints and knowledge about ergonomics of Internet Marketing Society workers. This service research uses observational methods from survey results with questionnaires distributed via a google form. The total respondents were 33 workers from the Internet Marketing Society. The results show that $54.5 \%$ of workers do not know about ergonomics, $75.8 \%$ of workers do not use wrist and arm support devices. In the complaint problem, most of the workers experienced muscle pain $27.3 \%$ and back pain $24.2 \%$, and $24.2 \%$ of workers experienced shoulder conditions that were not relaxed while working. Providing comprehensive knowledge and information related to ergonomics can certainly suppress complaints from workers to avoid MSDs. Then, the emphasis on occupational safety and health must be prioritized while working to avoid accidents or occupational diseases.

Keywords: Ergonomic; Safety first: Internet marketing society; MSDs

\section{PENDAHULUAN}

Komputer/laptop merupakan salah satu alat yang banyak digunakan pekerja baik di kantor atau di rumah. Tentu dalam penggunaannya membutuhkan komponen pendukung seperti mouse dan konektor monitor. Pekerja 
yang menggunakan computer tidak sedikit di era digital seperti saat ini. Revolusi industry 4.0 telah mendorong pekerja untuk lebih insten bekerja dengan perangkat computer. Terlepas dari produktivitas kerja yang meningkat dengan bantuan computer, tentu ada potensi-potensi bahaya yang tersembunyi.

Salah satu permasalahan kesehatan kerja dari penggunaan computer di tempat kerja telah berkontribusi menderita banyak risiko terkait MSDs (Musculoskeletal disorders) [1]. MSDs dikaitkan dengan isu kesehatan kerja pekerja. Diketahui dan diasumsi penyebab dari MSDs melingkupi aspek-aspek yang khusus dari lingkungan kerja, dan postur tubuh pekerja [2]. MSDs merupakan masalah kesehatan kerja terbesar di seluruh dunia [3]. Pekerjaan yang berkorelasi terjadinya MSDs ialah sebuah peristiwa yang digunakan untuk mendeskripsikan kondisi keparahan yang disebabkan di beberapa bagian tubuh, seperti tendon, otot, syarat, ligament, persendian, dan pembuluh darah, sebagai sebuah hasil dari aktivitas pekerjaan [4].

Pekerja-pekerja yang menderita MSDs memang belum dapat didata secara akurat, mengingat bahwa keluhan MSDs ada level ringan hingga berat yang dapat ditangani pekerja sendiri atau dengan meminta pertolongan ke tenaga medis. Berdasarkan hal diatas, MSDs juga sering terjadi pada bagian tubuh lainnya, antara lain: leher, bahu, siku, bagian bawah tubuh, pinggang, lutut, tulang paha, lengan bawah, dan pergelangan tangan [5], [6]. MSDs memberikan dampak merusak kesehatan dari pekerja-pekerja disemua lini pekerjaan, kemudian penelitian-penelitian empiris telah menyatakan bahwa MSDs sebagai salah satu penyakit yang termasuk mahal dan sering berhubungan pada penyakit akibat kerja [7].

Penyakit akibat kerja ialah penyakit yang didapatkan dari aktivitas kerja seperti halnya MSDs. Para pekerja terkadang belum tersadar bahwa mereka menderita MSDs tetapi tidak begitu memperhatikannya. Padahal jikalau dibiarkan begitu saja, MSDs dapat menyebabkan masalah kesehatan serius di masa mendatang. Kemudian, bagaimana rendahnya penggunaan teknologi dalam implementasi pengukuran keselamatan kerja dapat membuat kondisi lingkungan kerja tidak nyaman di negara-negara berkembang [8].

Bekerja didepan komputer dapat memberikan dampak buruk bagi kesehatan dan keselamatan pekerja. Potensi risiko bahaya dapat muncul terkait kecelakaan atau penyakit akibat kerja. Pekerja internet marketing society tentu saat mengerjakan pekerjaan dengan intensitas tinggi dan posisi postur statis dapat menimbulkan ketidaknyamanan pada beberapa bagian tubuh yang tergolong dalam MSDs. Penelitian study pendahuluan pengabdian ini untuk mengetahui besaran nilai pada sistem kerja pekerja dan direkomendasikan untuk intervensi cara pencegahan dalam menurunkan dampak buruk bekerja di depan komputer.

\section{METODE}

Penelitian ini dilakukan atas permintaan dari pengurus Internet Marketing Society yang bekerjasama dengan peneliti untuk mengintervensi tingkat ergonomi pekerja. Sehingga dilakukan studi pendahuluan untuk menganalisis masalah keluhan ergonomi di pekerja sebelum melakukan intervensi. Study pendahuluan pengabdian ini menggunakan metode yang dijelaskan dibawah ini:

\subsection{Objek Penelitian}

Objek penelitian merupakan pekerja yang tergabung di Internet Marketing Society. Pekerja ini dari berbagai kalangan pekerjaan yang berbasis internet marketing, seperti pekerja olshop (online shopping), pasar modal, krypto, dan lain-lain. Responden merupakan pekerja yang berasal dari Purwokerto, Banyumas, Jawa Tengah. Keseharian responden selalu terhubung dengan komputer saat bekerja. Kemudian, responden di dominasi pekerja laki-laki dibandingkan perempuan.

\subsection{Sampling}

Pada penelitian ini mengikutsertakan semua anggota pekerja dari Internet Marketing Society yang berjumlah 33 orang. Sehingga, semua responden telah dilibatkan pada studi ini dengan rincian 21 laki-lai dan 12 perempuan. Responden mempunyai latar belakang pendidikan yang bermacam-macam, dengan paling rendah SMA/SMK/MA dan tertinggi Strata-1. Semua responden harus sesuai dengan kriteria inklusi, yaitu:

a. Aktif bekerja dengan komputer

b. Tergabung dengan Internet Marketing Society

c. Bersedia mengisi kuesioner angket

\subsection{Pengumpulan Data} yaitu:

Pada study pendahuluan pengabdian yang berbasis penelitian ini dikumpulkan data dengan beberapa cara

a) Data Primer 
Data Primer didapatkan secara langsung dari responden dengan melaksanakan observasi ke responden dengan kuesioner melalui google form yang telah disiapkan sebelumnya. Penelitian ini dilakukan atas permintaan dari pengurus Internet Marketing Society yang bekerjasama dengan peneliti untuk mengintervensi tingkat ergonomi. Sehingga dilakukan studi pendahuluan untuk menganalisis masalah keluhan ergonomi di pekerja sebelum melakukan intervensi.

b) Data Sekunder

Data Sekunder didapatkan melalui artikel-artikel yang relevan dengan pengabdian berbasis penelitian ini.

\subsection{Pengolahan dan Analisis Data}

Pengolahan data pada pengabdian ini dilaksanakan dengan menggunakan komputerisasi. Penyampaian hasil data dengan bentuk tabel dan dideskripsikan sesuai hasil lapangan yang telah ditetapkan.

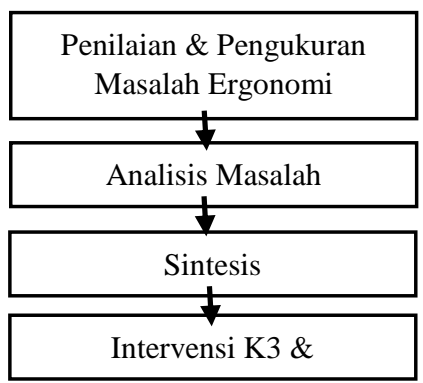

Gambar 1. Diagram Alir Penelitian Pendahuluan Pengabdian

Pengabdian ini dilaksanakan berdasarkan ilustrasi diagram alir tersebut. Studi pendahuluan ini dilakukan untuk mengetahui intervensi yang sesuai dengan permasalahan yang dihadapi responden. Tentu dalam studi ini yang ingin dicapai mengetahui secara detail masalah-masalah di tempat kerja responden. Studi ini melibatkan pengurus Internet Markteting Society untuk menyebarluaskan kuesioner untuk menilai dan mengukur tingkat masalah kesehatan dan keselamatan kerja responden. Kontribusi studi ini agar nantinya mendapatkan formula intervensi secara adequate dan memberikan dampak nyata pada tingkat derajat kesehatan responden di masa mendatang.

\section{HASIL DAN PEMBAHASAN}

Pada hasil penelitian pengabdian ini total responden 33 pekerja yang mengisi kuesioner yang disebarkan melalui google form. Hal ini tidak mengurangi esensi akurat pada hasil survey ini. Pekerja yang tergabung pada Internet Marketing Society merupakan pekerja dengan berbagai macam pekerjaan yang freelance. Salah satu pekerjaannya, pialang pasar modal hanya lewat komputer di rumah, bisnis kripto, pengusaha marketplace, dan masih banyak lainnya.

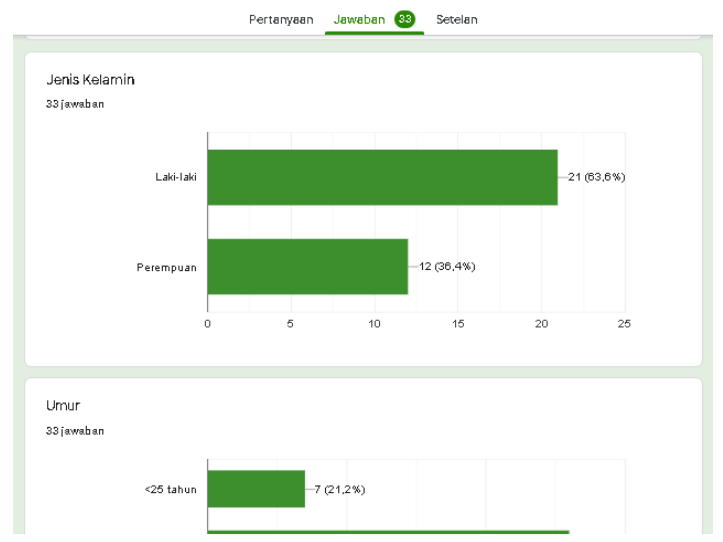

Gambar 2. Jumlah Total Jawaban Responden Pekerja Internet Marketing Society

Gambar 1 menunjukkan email dari para pekerja yang telah mengisi kuesioner dengan sukarela yang dibagikan pengurus komunitas ke anggotanya. Sistem kuesioner tidak bisa dilakukan dengan wawancara 
langsung terkendala masih masa pandemic. Ada 33 jawaban dari 33 email pekerja yang terekam di dalam google drive peneliti.

a. Data Karakteristik Responden

Tabel 1. Karakteristik Responden Pekerja Internet Marketing Society

\begin{tabular}{lll}
\hline No & Keterangan & Persentase $(\%)$ \\
\hline 1 & Jenis Kelamin & \\
& Laki-laki & $21(63,6 \%)$ \\
& Perempuan & $12(36,4 \%)$ \\
2 & Umur & \\
& $<25$ tahun & $7(21,2 \%)$ \\
& $25-35$ tahun & $26(78,8 \%)$ \\
& $36-45$ tahun & 0 \\
3 & Lama Kerja & \\
& $<1$ tahun & $7(21,2 \%)$ \\
& $1-3$ tahun & $7(21,2 \%)$ \\
& $3-5$ tahun & $11(33,3 \%)$ \\
& $>5$ tahun & $8(24,2 \%)$ \\
4 & Durasi Kerja Komputer & \\
& $<5$ tahun & $10(30,3 \%)$ \\
& $5-8$ jam & $17(51,5 \%)$ \\
& $8-10$ jam & $7(21,2 \%)$ \\
5 & Pengetahuan Ergonomi & $18(48,5 \%)$ \\
& Tahu &
\end{tabular}

Pada Tabel 1 menunjukkan karakteristik dari responden pekerja yang terlihat lebih banyak berjenis kelamin laki-laki 63,6\% dibandingkan perempuan 36,4\%. Dari indikator usia menyatakan bahwa pekerja lebih banyak di rentang usia 25 - 35 tahun 78,8\% dengan lama kerja lebih banyak disekitar 3-5 tahun. Sedangkan durasi kerja harian 5-8 jam $(51,5 \%)$ dan pengetahuan tentang ergonomic saat bekerja lebih banyak tidak mengetahuinya $54,5 \%$.

Karakteristik diatas mengungkapkan bahwa para pekerja tergolong usia relative muda dan usia produktif. Data diatas juga menyatakan jikalau pengetahuan mengenai ergonomic yang rendah dari kalangan pekerja. Tentu jika ditemukan beberapa penyakit akibat kerja bukanlah tidak mungkin tidak terjadi.

b. Data Identifikasi Problem Responden

Tabel 2. Identifikasi Problema Responden Pekerja Internet Marketing Society

\begin{tabular}{lll}
\hline Hal yang Diamati & \multicolumn{2}{l}{ Kesesuaian Kondisi } \\
Keyboard \& Mouse & Ya (\%) & Tidak (\%) \\
\hline $\begin{array}{l}\text { Apakah keyboard dan mouse berada pada posisi } \\
\text { yang sama dan berdekatan satu sama lain? }\end{array}$ & \multicolumn{1}{l}{12,1} \\
$\begin{array}{l}\text { Apakah terdapat lahan pada meja yang dapat } \\
\text { mendukung pergelangan tangan Anda saat bekerja? }\end{array}$ & 63,9 & 6,1 \\
$\begin{array}{l}\text { Apakah bahu Anda berada pada posisi yang rileks } \\
\text { saat Anda bekerja? }\end{array}$ & 75,8 & 24,2 \\
$\begin{array}{l}\text { Apakah posisi keyboard yang Anda gunakan } \\
\text { mendatar? }\end{array}$ & 78,8 & 21,2 \\
$\begin{array}{l}\text { Apakah terdapat alat pendukung lain yang } \\
\text { menyangga pergelangan dan lengan Anda saat }\end{array}$ & & \\
\hline
\end{tabular}


bekerja dengan menggunakan keyboard?

Pada Tabel 2 menyatakan bahwa masalah responden sebagian besar tidak menggunakan alat pendukung lain dalam menciptakan keergonomisan pergelangan dan lengan saat sedang bekerja (75,8\%) dan posisi keyboar mendatar (78,8\%). Tetapi beberapa indikator pekerja sudah sesuai dengan kondisi seperti keyboar dan mouse ada di posisi berdekatan $(87,9 \%)$, meja kerja ada lahan untuk pergelangan $(93,9 \%)$ dan bahu pekera dengan posisi rileks $(75,8 \%)$, Tentu hal ini sudah terlihat hampir dari indikator tidak mengalami ketidaksesuaian kondisi ergonomic di pekerja.

Ada beberapa indikator diatas yang menjadi masalah jikalau pekerja lebih banyak menjawab TIDAK, tetapi ada satu indikator yang kalau pekerja menjawab YA pada pertanyaan posisi keyboard yang mendatar. Padahl seharusnya keyboard yang ergonomic sedikit miring dengan sudut $3^{\circ}-12^{\circ}$ [9].

c. Data Distribusi Keluhan Kerja Responden

Tabel 3. Distribusi Keluhan Responden Pekerja Internet Marketing Society

\begin{tabular}{lll}
\hline Jenis Keluhan & Frekuensi & Persentase $(\%)$ \\
\hline Kelelahan & 4 & 12,1 \\
Gangguan penglihatan & 3 & 9,1 \\
Nyeri otot & 9 & 27,3 \\
Pusing & 3 & 9,1 \\
Dehidrasi & 2 & 6,1 \\
Konsentrasi kerja menurun & 2 & 6,1 \\
Nyari punggung & 8 & 24,2 \\
Kram pada kaki & 2 & 6,1 \\
Jumlah & 33 & 100 \\
\hline
\end{tabular}

Pada Tabel 3 mengatakan bahwa ada beberapa indikator keluhan yang sering diderita pekerja. Ternyata ditemukan dari hasil survey bahwa pekerja sering menderita nyeri otot pergelangan $(27,3 \%)$ dan nyari punggung $(24,2 \%)$. Selain itu, keluhan kelelahan $(12,1 \%)$ juga banyak diderita para pekerja. Keluhan-keluhan hasil survey selaras dengan MSDs. Hal ini ditemukan perlu adanya implementasi prinsip ergonomic saat bekerja yang salah satunya menstimulasi tugas-tugas pekerjaan harus diadaptasi dari pekerja dan juga diperkirakan pekerjaan dalam zona nyaman [10]. Ditambahkan, durasi bekerja yang mempunyai waktu istirahat sedikit dengan lamanya bekerja sangat relevan berhubungan dengan menderita MSDs, yang salah satunya mengindikasikan pendeknya waktu istirahat, rendahnya kemungkinan otot untuk recovery dari stress dan ketegangan dari bekerja [11], [12].

Data Tabel 3 lebih khusus pada penyakit akibat kerja yang telah diderita pekerja selama sedang bekerja. Keluhan semacam itu perlu adanya tindakan segera untuk dilakukan pencegahan dan promotive untuk meningkatkan derajat kesehatan pekerja. Pentingnya pemberian pemahaman dan pengetahuan betapa pentingnya peralatan keselamatan pendukung saat sedang bekerja [13]. Terlebih pekerja yang dibawah naungan Internet Marketing Society termasuk komunitas independen yang bekerja secara freelance, sehingga sangat membutuhkan intervensi prinsip K3 dan ergonomi.

\section{KESIMPULAN}

Hasil penelitian menyatakan bahwa ada dua keluhan yang paling sering terjadi/dirasakan pekerja saat bekerja menggunakan komputer yaitu keluhan nyeri otot dan punggung. Selain itu, pekerja sebagian besar tidak tahu terkait ergonomi. Kemudian pekerja juga tidak menambahkan alat penyangga pergelangan dan lengan ketika sedang bekerja. Hal ini tentu membutuhkan suatu intervensi secara nyata pada implementasi prinsipprinsip kesehatan keselamatan kerja dan ergonomic di pekerja internet marketing society.

\section{DAFTAR PUSTAKA}

[1] M. Matos and P. M. Arezes, "Ergonomic evaluation of office workplaces with Rapid Office Strain Assessment ( ROSA )," Procedia Manuf., vol. 3, pp. 4689-4694, 2015.

[2] M. Massiris, J. Á. Fernández, J. M. Bajo, and C. A. Delrieux, "Ergonomic risk assessment based on computer vision and machine learning," Comput. Ind. Eng., vol. 149, no. December 2019, pp. 1-11, 2020. 
[3] Y. Ayub and Z. A. Shah, "Assessment of Work Related Musculoskeletal Disorders in Manufacturing Industry," J. Ergon., vol. 8, no. 3, pp. 1-5, 2018.

[4] H. Russell, B. Maître, and D. Watson, "Work-related Musculoskeletal Disorders and Stress, Anxiety and Depression in Ireland: Evidence from the QNHS 2002 - 2013," Econ. Soc. Res. Inst., no. 5, pp. 1-8, 2016.

[5] R. Z. Hamid and H. Y. Mohammad, "Work related musculoskeletal disorders in Iranian dentistry: systematic review and meta-analysis," Elsevier J. Saf. Heal. Work, vol. 9, no. 1, pp. 1-9, 2017.

[6] H. Executive, Safety, "Work Related Musculoskeletal Disorders in Great Britain," Health Safety Environment, 2017. [Online]. Available: www.hse.gov.nklstatistics.

[7] K. Orhan and A. M. Asad, "Introductory Chapter: Work-related Musculoskeletal Disorders," 2019. [Online]. Available: https://www/intechopen.com/books/work-related-musculoskeletaldisorders/introductory-chapter-work-related-musculoskeletal-disorders.

[8] K. A. U, HaliruLadan, R. M. O, A. U. M, and A. J. T, "Knowledge , Perception and Practice of Safety Measures Related to Workplace Hazards among Manual Stone Crushing Workers in Sokoto, Nigeria," Int. J. Occup. Saf. Heal., vol. 8, no. 1, pp. 8-18, 2018.

[9] A. N. Aisha, “OFFICE ERGONOMICS ASSESSMENT PADA KANTOR BANK X," J. Rekayasa Sist. Ind., vol. 1, no. 1, pp. 68-74, 2014.

[10] M. Middlesworth, "Fundamental ergonomic principles for better work performance," ErgoPlus.com, 2020. [Online]. Available:

https://ergo-plus.com/fundamental-ergonomic princip\%0Ales/\#: :text $1 / 4$ Principle $\% 25201$.\&text $1 / 4$ Neutral $\% 2520$ postures $\% 2520$ are $\% 2520$ postures $\% 25 \% 0$ A20where,maximum\%2520control\%2520and\%2520force\%2520production.

[11]P. Yan et al., "Prevalence of Work-Related Musculoskeletal Disorders in the Nurses Working in Hospitals of Xinjiang Uygur Autonomous Region,” Sci. World J., vol. 2017, pp. 1-7, 2017.

[12] A. Alghadir and S. Anwer, "Prevalence of Musculoskeletal Pain in Construction Workers in Saudi Arabia," Sci. World J., vol. 2015, pp. 1-5, 2015.

[13]D. B. Sidharta, S. Kelana, and S. P. Sutrisno, "Peningkatan kesadaran penggunaan alat keselamatan pelayaran bagi nelayan di kabupaten musi banyuasin," Kacanegara J. Pengabdi. pada Masy., vol. 4, no. 1, pp. 125-132, 2021. 